\title{
Unusually High Intra-abdominal Opening Pressure Confirmed by Simultaneous Gastric Pressure Measurement during Laparoscopy
}

\author{
Richard Matulewicz ${ }^{\mathrm{a}, *}$, Antonio R. Gargiulo ${ }^{\mathrm{b}}$, Stephen H. Loring ${ }^{\mathrm{c}}$ and Massimo Ferrigno ${ }^{\mathrm{a}}$
}

\begin{abstract}
${ }^{a}$ Department of Anesthesiology, Perioperative and Pain Medicine and ${ }^{b}$ Department of Obstetrics, Gynecology and Reproductive Biology, Brigham and Women's Hospital, Harvard Medical School, Boston, MA, USA; 'Department of Anesthesia, Critical Care \& Pain Medicine, Beth Israel Deaconess Medical Center, Harvard Medical School, Boston, MA, USA
\end{abstract}

\begin{abstract}
A 28 year-old obese woman was scheduled for robot-assisted bilateral tubal re-anastomosis under general anesthesia and neuromuscular blockade. As part of a respiratory mechanics study, gastric pressure (Pga) was measured. At the beginning of the operation, the surgeon repeatedly inserted a Veress needle consistently measuring an unusually high opening pressure of $15 \mathrm{mmHg}$, at a time when Pga was $12.5 \mathrm{mmHg}$. Based on the elevated Pga values, we inferred that the high opening pressure was a valid intra-peritoneal pressure, rather than a sign of incorrect needle placement; therefore, the surgeon proceeded with uneventful insufflation of the peritoneal cavity. This patient exhibited an unusually high opening intra-abdominal pressure that likely reflected her high degree of central obesity. Simultaneous Pga determination proved valuable in confirming intra-peritoneal location of the tip of Veress needle and may be a viable method of corroborating high opening pressures despite safe needle positions in laparoscopic cases.
\end{abstract}

Keywords: Laparoscopic surgery, truncal obesity, central obesity, respiratory mechanics, intraperitoneal pressure.

\section{INTRODUCTION}

Pneumoperitoneum is routinely used by surgeons to facilitate organ visualization and surgical manipulations during laparoscopic procedures. An opening intra-abdominal pressure of $12 \mathrm{mmHg}\left(16.3 \mathrm{~cm} \mathrm{H}_{2} \mathrm{O}\right)$ or less at the time of insufflation with the Veress needle is considered physiological [1]. This also applies to morbidly obese patients as well, although it has been shown that this particular patient population has a higher baseline intraabdominal pressure (IAP) (approximately $8-9 \mathrm{mmHg}$ ) [2]. An opening pressure $>12 \mathrm{~mm} \mathrm{Hg}$ may indicate an incorrect location of the needle, including pre-abdominal, intraadhesion, or even intra-organ [3]. Extraperitoneal insufflation with abdominal wall emphysema has been described as one of the most common complications leading to abandonment of the laparoscopic approach, particularly in obese patients [4]. Still, obese patients who undergo laparoscopy have shorter hospital stay, less postoperative pain and fewer wound infections than obese patients undergoing laparotomy: hence, laparoscopy has become a surgical modality of choice particularly in obese patients [5].

\section{CASE REPORT}

A 28 year old obese multiparous woman $(\mathrm{H}: 150 \mathrm{~cm}$; W: $74.8 \mathrm{~kg}, \mathrm{BMI}=34.8$ ) was scheduled for robot-assisted laparoscopic bilateral tubal re-anastomosis. After induction of general anesthesia and endotracheal intubation, mechanical ventilation was started while neuromuscular blockade was

*Address correspondence to this author at the Department of Anesthesia, Brigham and Women's Hospital, 75 Francis St, Boston, MA 02115, USA; Tel: 617-732-8210; Fax: 617-730-9534;

E-mail: richard.matulewicz@gmail.com maintained. As part of a study of respiratory mechanics during laparoscopic surgeries requiring both Trendelenburg position and pneumoperitoneum, a $9.5 \mathrm{~cm}$ long esophageal balloon (Ackrad Laboratories, Cranford, NJ) was passed through the mouth and taped at the incisors at $40 \mathrm{~cm}$ from the tip of the balloon for the measurement of esophageal pressure (Pes) in the lower third of esophagus [6]. Pressure in this balloon, inflated with $0.5 \mathrm{ml}$ of air, and pressure at the airway (Paw) were measured with transducers (Validyne Type 45-14, Harvard Apparatus, Holliston, MA) and recorded and displayed on a laptop computer using Windaq software and hardware (Dataq Instruments, Akron, $\mathrm{OH}$ ). Because of malfunction of our pneumotachometer system, tidal volumes were measured by the ventilator (Aisys, Datex-Ohmeda, Madison WI).

Based on intra-operative pressures and waveforms, we inferred that the esophageal balloon had actually passed into the stomach, where it was measuring gastric pressure (Pga). A comparison of a typical esophageal pressure measurement (Fig. 1, upper panel) shows Pes changing with ventilation and PEEP, whereas the relatively high gastric pressure in this patient (Fig. 1, lower panel, red tracing) did not increase when PEEP was applied at the airway (Paw, blue tracing).

At the beginning of surgery, with the patient in dorsal lithotomy position on a leveled table, the surgeon inserted the Veress needle through a small incision in the lower umbilical fornix. Because of her high BMI, the needle was angled perpendicular to the plane of the patient. A $10 \mathrm{ml}$ syringe containing $5 \mathrm{ml}$ of normal saline solution was connected to the LuerLock of the Veress needle: after aspiration had yielded no fluid or blood, $5 \mathrm{ml}$ of normal saline were injected without any perceived resistance and 



Fig. (1). Upper panel: Pes tracing on a representative patient in $54^{\circ}$ Trendelenberg position and pneumoperitoneum inflated to $15 \mathrm{~cm} H 2 \mathrm{O}$. Lower panel: Simultaneous recordings of gastric (Pgastric, red) and airway (Pairway, blue) pressures in our patient, in Trendelenburg position $\left(29^{\circ}\right)$ and with pneumoperitoneum $(20 \mathrm{mmHg})$, with different levels of PEEP. This figure indicates a stable and elevated gastric pressure in the setting of progressively increasing levels of PEEP consistent with a post pyloric position of the balloon and increased IAP.

could not be drawn back. However, in spite of these findings, an unusually high opening pressure of $15 \mathrm{mmHg}$ was recorded by the manometer of the insufflation unit. As opening pressures above $12 \mathrm{mmHg}$ are considered a possible indication of either pre-peritoneal or intra-visceral insertion, it is generally considered unsafe to proceed with insufflation of the abdominal cavity for laparoscopy [3]. Therefore, the surgeon inserted the Veress needle two more times through the same incision but at different angles: $30^{\circ}$ caudad and cephalad from the perpendicular line, respectively. However, these insertions also yielded an intra-abdominal pressure of $15 \mathrm{mmHg}$. Eventually, the Veress needle was inserted in left subcostal area on the mid-clavicular line (Palmer's point), with the same high opening pressure reading. At the same time, our recordings showed a Pga of $\sim 17 \mathrm{cmH}_{2} \mathrm{O}(12.5$ $\mathrm{mmHg}$ ) at end-expiration with a Tidal Volume of $\sim 360 \mathrm{ml}$ and Positive End-Expiratory Pressure (PEEP) of $5 \mathrm{cmH}_{2} \mathrm{O}$, and Peak Inspiratory Pressures of $\sim 38 \mathrm{cmH}_{2} \mathrm{O}$. Based on the elevated Pga measurements, we agreed that the high opening pressure was physiological, rather than caused by incorrect position of the Veress needle. Therefore, pneumoperitoneum was produced with insufflation of $\mathrm{CO}_{2}$, to an intraperitoneal pressure of $20 \mathrm{mmHg}$, after which the surgeon inserted a trocar and a laparoscope that confirmed entry into the peritoneal cavity through Palmer's point. The operation was continued and it was completed uneventfully using an intraperitoneal pressure of $20 \mathrm{mmHg}$. 


\section{DISCUSSION}

In the case reported here, the simultaneous measurement of Pga allowed confirmation of correct position of the tip of the Veress needle, in spite of an unusually high opening intra-abdominal pressure $(15 \mathrm{mmHg})$. An esophageal balloon had been inserted $40 \mathrm{~cm}$ from the tip of the balloon with the goal of measuring pressure in the lower third of the esophagus [7] but, in this unusually short-statured patient, it had actually entered the stomach.

In the clinical settings, intra-abdominal pressure (IAP) is frequently measured through a urinary bladder catheter. With this technique, which included emptying the bladder then subsequently irrigating with 50cc of normal saline, Sanchez et al., [8] measured in 52 non-obese individuals an average IAP of $5 \mathrm{mmHg}$, with a wide range of 0.2 to $11.8 \mathrm{mmHg}$. They also found a positive correlation between IAP and a patient's body mass index (BMI), with average pressures of 8.9 [range 4.5 to $16.2 \mathrm{mmHg}$ ] and $8.4 \mathrm{mmHg}$ [range 4.7 to $10.2 \mathrm{mmHg}$ ] in obese and morbidly obese patients, respectively. It could be argued that the large variability in these measurements of IAP may be due to different distributions of fat in those patients. In particular, when fat is localized around the waist and in the upper part of the body as in android obesity (observed most commonly in men), IAP may be more elevated than when a patient with the same BMI exhibits gynoid obesity (most frequently observed in women), in which fat is distributed in the lower portion of the body [9]. In fact, Sugerman et al., found a correlation between sagittal abdominal diameter and IAP measured in the urinary bladder in both male and female morbidly obese patients [10]. This was confirmed by Lambert et al., as well [2]. Recently, Behazin et al., [11] have described a large range of intra-abdominal pressure, measured in the stomach (i.e., Pga) at end-exhalation in 30 obese subjects. In their study, $\mathrm{Pga}$ ranged from 6.7 to $17 \mathrm{cmH}_{2} \mathrm{O}$ (4.93 to 12.5 $\mathrm{mmHg}$, with an average of $11.5 \mathrm{cmH}_{2} \mathrm{O}(8.45 \mathrm{mmHg})$. While it is assumed that Pga and pressure in the urinary bladder are equivalent in assessing IAP [10], it is important to note that measurements of IAP taken at different locations within the abdominal cavity (for example, opening IAP measured through a Veress needle inserted at periumbilical area vs. Pga) will be affected by the gravitational pressure gradient inside the abdomen. Body position, for example, Trendelenburg vs. reverse-Trendelenburg or even lateral decubitus positions will affect in different ways both gastric and urinary bladder pressure measurements.

The high opening IAP measured in this patient (15 $\mathrm{mmHg}$ ) was probably related to her body habitus. Even though her BMI was only slightly elevated (BMI: 33.3 $\mathrm{kg} / \mathrm{m}^{2}$, i.e., Class I obesity), she exhibited a high degree of truncal obesity, as reflected by her very high Index of Central Obesity (ICO) of 0.61 , derived from the ratio of waist circumference and height [12]. Our patient also exhibited a restrictive respiratory pattern with high peak inspiratory pressures despite small tidal volumes, also consistent with abdominal obesity [11]. In the literature, abdominal compartment syndrome [13], characterized by the high IAP values in the patient described here, is associated with serious respiratory, renal, liver and cardiovascular derangements $[14,15]$. It is reasonable to assume that the chronic nature of our patient's condition had led to compensatory mechanisms of respiratory and other organ systems affected by her abdominal obesity. Still, there is recent evidence that a large waist circumference is associated with an increased risk of death from any cause among nonobese women, at least in the black population studied [16].

The possibility of unusually high opening abdominal pressures during laparoscopic procedures in obese patients should be taken into account by surgeons when evaluating correct position of the tip of the Veress needle, before insufflation to produce pneumoperitoneum. Furthermore, we have shown that comparison between the pressure measured via Verres needle with available, indirect measurements of peritoneal pressure such as gastric pressure might be a viable approach to confirm the intraperitoneal position of the needle.

\section{SUPPORT}

The study to which this case report refers was supported by funds from the Department of Anesthesiology, Perioperative and Pain Medicine at the Brigham and Women's Hospital in Boston, MA.

\section{CONFLICT OF INTEREST}

Declared none.

\section{ACKNOWLEDGEMENT}

Declared none.

\section{REFERENCES}

[1] Poindexter AN, Ritter M, Fahim A, Humphrey H. Trocar introduction performed during laparoscopy of the obese patient. Surg Gynecol Obstet 1987; 165: 57-59.

[2] Lambert DM, Marceau S, Forse RA. Intra-abdominal pressure in the morbidly obese. Obes Surg 2005; 15: 1225-32

[3] Park, Cadeddu. "Complications of Minimally Invasive Surgery." Complications of Urologic Surgery and Practice: Diagnosis, Prevention, and Management. Ed. Kevin R. Loughlin. New York: Informa Healthcare 2007; 428.

[4] Mumford SD, Bhiwandiwala, Chi IC. Laparascopic and minilaparatomy female sterilisation compared in 15167 cases. Lancet $1980 ; 2: 1066-70$.

[5] Lamvu G, Zolnoun D, Boggess J, Steege JF. Obesity: physiologic changes and challenges during laparoscopy. Am J Obstet Gynecol 2004; 191: 669-74.

[6] Fry DL, Stead WW, Ebert RV, Lubin RI, Wells HS. The measurement of intraesophageal pressure and its relationship to intrathoracic pressure. J Lab Clin Med 1952; 40: 664-73.

[7] Talmor D, Sarge T, Malhotra A, et al. Mechanical ventilation guided by esophageal pressure in acute lung injury. N Engl J Med 2008; 359: 2095-104.

[8] Sanchez NC, Tenofsky PL, Dort JM, Shen LY, Helmer SD, Smith RS. What is normal intraabdominal pressure? Am Surg 2001; 67: 243-8.

[9] Vague J. The degree of masculine differentiation of obesities. Am J Clin Nutr 1956; 4(1): 20-34.

[10] Sugerman H, Windsor A, Bessos M, Wolfe L. Intra-abdominal pressure, sagittal abdominal diameter and obesity comorbidity. J Int Med 1997; 241: 71-9.

[11] Behazin N, Jones SB, Cohen I, Loring SH. Respiratory restriction and elevated pleural pressure and esophageal pressures in morbid obesity. J Appl Physiol 2010; 108: 212-8.

[12] Parikh RM, Joshi SR, Menon PS, Shah NS. Index of central obesity-A novel parameter. Med Hypotheses 2007; 68: 1272-75. 
[13] Schein M, Wittmann DH, Aprahamian CC et al. The abdominal compartment syndrome: the physiological and clinical consequences of elevated intra-abdominal pressure. J Am Coll Surg 1995; 180: 745-53.

[14] Canoy D, Luben R, Welch A, et al. Abdominal obesity and respiratory function in men and women in the epic-norfolk study, United Kingdom. Am J Epidemiol 2004; 159(12): 1140-9.
[15] Saggi BH, Sugerman J, Ivatury RR, et al. Abdominal compartment syndrome. J Trauma 1998; 45: 597-609.

[16] Boggs DA, Rosenberg LR, Cozier YC, et al. General and abdominal obesity and risk of death among black women. $\mathrm{N}$ Engl $\mathbf{J}$ Med 2011;365; 10: 901-8

Received: October 25, 2011

(C) Matulewicz et al.; Licensee Bentham Open.

This is an open access article licensed under the terms of the Creative Commons Attribution Non-Commercial License (http://creativecommons.org/licenses/ by-nc/3.0/) which permits unrestricted, non-commercial use, distribution and reproduction in any medium, provided the work is properly cited. 